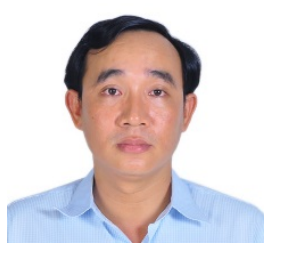

\title{
Not Enough Time to Teach Pronunciation? Build Student Autonomy
}

\author{
Quyet Nguyen \\ Thoai Ngoc Hau High School for the Gifted, An Giang Province
}

\begin{abstract}
In Vietnam, teaching pronunciation is mostly marginalized. Many teachers complain about not having enough time to teach pronunciation in their classrooms. Also, assessing pronunciation is not necessarily a straightforward process. To solve this problem, the presenter outlines an approach to build student autonomy in learning pronunciation.
\end{abstract}

\section{Session Description}

It has been believed for a long time that students cannot learn pronunciation on their own since they need teachers to give them models and feedback, especially in countries where English is not spoken outside the classroom. Recently, computer-assisted pronunciation teaching strategies were found to have a significant effect on the learners’ perception and production of key suprasegmental features (Tanner and Landon, 2009). Furthermore, student motivation in learning is said to be one of the key factors in whether or not they will succeed in building their autonomy. After attending the session, participants will be able to identify ways to help students build their autonomy in learning English pronunciation. The presenter addresses interesting ways to encourage students to self-study pronunciation. The presenter also provides examples of computer-assisted techniques through which students can access models of native English speakers’ speech in such formats as dictionaries, websites, and other computer-based tools. For practicing pronunciation, the presenter demonstrates ways for students to practice articulating particular segmental as well as suprasegmental features ranging from the word to the paragraph. In addition, the presenter discusses useful and practical technology-based tools to help students self-analyze their mistakes at the segmental and suprasegmental levels. Students will see and hear their mistakes and be able to correct their own pronunciation errors. Aside from using technology to build student autonomy in learning, pronunciation is also discussed in this session in terms of peer instruction. Yerian (2014) found that when students become more relaxed in the instruction and practice of pronunciation, they can 
become autonomous learners. This presentation will be very helpful to EFL and ESL teachers who wish to help students improve their pronunciation.

\section{References}

Tanner, M. W., \& Landon, M. M. (2009). The Effects of Computer-Assisted Pronunciation Readings on ESL Learners’ Use of Pausing, Stress, Intonation, and Overall Comprehensibility. Language Learning \& Technology 13, 51-65.

Yerian, K. (2014). Learners can teach pronunciation, too: Building autonomy through peer instruction. Tesol International Association. Retrieved February 2, 2016, from http://newsmanager.commpartners.com/tesolsplis/issues/2014-10-06/3.html 